This is a peer-reviewed, accepted author manuscript of the following conference paper: Puliyaneth, M., Chen, H., \& Luan, W. (2019). Cyclic plasticity analysis of welded joint with welding residual stress using the direct method. In ASME 2019 Pressure Vessels \& Piping Conference: Volume 6A: Materials and Fabrication New York: ASME. https://doi.org/10.1115/PVP2019-93228 C ASME 2019

\title{
CYCLIC PLASTICITY ANALYSIS OF WELDED JOINT WITH WELDING RESIDUAL STRESS USING THE DIRECT METHOD
}

\author{
Manu Puliyaneth \\ Department of Mechanical \& Aerospace \\ Engineering, University of Strathclyde, Glasgow,
}

G1 1XJ, UK

\author{
Haofeng Chen* \\ Department of Mechanical \& Aerospace \\ Engineering, University of Strathclyde, Glasgow, \\ G1 1XJ, UK
}

\author{
Weiling Luan \\ School of Mechanical and Power \\ Engineering, East China University of \\ Science and Technology, 130 \\ Meilong Rd. Shanghai 200237, \\ China
}

\section{ABSTRACT}

To meet the growing energy demands, the power sector continuously strives at enhancing the efficiency of its power plants by increasing the operating temperature. Under cyclic loading conditions, this leads to creep-cyclic plasticity driven damage mechanisms such as cyclically enhanced creep, creep enhanced plasticity and creep ratcheting. A detailed understanding of creep and related damages is therefore essential for predicting any potential failure mechanisms and ensuring confidence in the safe-working of the components. This becomes particularly difficult and challenging in the presence of welds due to two main reason; a) presence of different material zones, namely parent metal, weld metal and heat affected zone; b) introduction of residual stress during welding. An extended Direct Steady Cycle Analysis within the Linear Matching Method (LMM) framework has been previously developed to consider the full interaction between creep and cyclic plasticity. This paper presents the basic theory and an overview behind the LMM framework along with a new application of a welded flange, considering for the first time the effect of residual stress due to welding. A 3D finite element model is adopted for the flange, and it is subjected to a constant pressure and cyclic thermal load of

varying dwell. The effects of welding residual stress on the creep-cyclic plastic response of the welded flange are investigated. Additional parametric studies considering different levels of the applied load and dwell period are performed. The results reflect the ease of using LMM over conventional inelastic analysis.

Keywords: Creep; Creep - Cyclic Plasticity Interaction; Creep-Fatigue Damage; LMM; Residual Stress; Weld

\section{NOMENCLATURE}

Q

$\mathrm{V}$

I

$\eta$

$v$

$\mathrm{t}$

$f_{f}, f_{r}$

$\mathrm{a}_{\mathrm{f}}, \mathrm{a}_{\mathrm{r}}$

$\mathrm{b}$

c
$=$ Input power of the welding heat source

$=$ Arc voltage

$=$ Welding current

$=$ Process efficiency

$=$ Welding speed

$=$ Current time

$=$ Heat fraction parameters in the front quadrant and rear quadrants $=$ Length of front and rear ellipsoidal

$=$ Depth of the heat source

$=$ Width of the heat source 


\section{INTRODUCTION}

Components used in power plants are complex in nature and generally of large size, hence manufacturing practices such as forging is not always possible, making welding the preferred fabrication process. This may induce residual stress within the structure. While investigating failure mechanisms and life to failure of components within the power plant sector, the most common practice is to consider the effects of external loading but it has been reported that various other factors such as defects or the presence of residual stress too can influence the life of a component. Structural integrity study of welded joint is an area of interest and concern within both academia and industry as they have been reported to be a potential location for creep-fatigue damage under cyclic loading conditions. This can be attributed to two main factors; a) a weldment consists of different material zones which lead to stress concentration; and b) the presence of residual stress induced due to welding. Residual stress can be defined as the stress that is retained within the structure when it is stationary and at equilibrium with its surroundings [1]. The effect of residual stress on structural integrity has received less attention compared to other failure contributing factors. One of the main reason for this is the difficulty in its measurement and prediction [2]. Depending on the sign/direction of the residual stress, they may add on or subtract from the applied load. Residual stress in welds generally have a detrimental effect whereas they can be exploited in a positive way in cases where the components are resistant to damage [1]. Hence assessing the residual stress accurately and investigating their effect when combined with the applied load on the life of the component are essential in evaluating the safe life of the component [2]. Pipe-flange joints are an integral part of piping systems in power plants. They are generally used for pipe-pipe connections, pipe-valve connections etc. Considering their importance and relevance within a piping system, a welded flanged joint is considered as the case study of this work.

The Linear Matching Method is among the prominent direct method tools that are used in conjunction with FE modeling for structural integrity and life assessment. The LMM ABAQUS user subroutines for limit load analysis and shakedown analysis have been consolidated by the R5 research program of EDF Energy to the commercial standard. The LMM has been recently developed to include the extended Direct Steady Cycle Analysis (eDSCA) for the evaluation of creep-fatigue interaction [3] and have been validated for different practical problems in [4-7]. But none of the studies conducted earlier considered the effect of welding residual stress on the creep-cyclic plasticity of welded joints. Hence the aim of this paper is to adopt the eDSCA within the LMM framework to access the steady- state cyclic response of a welded joint with welding residual stress, subjected to a cyclic thermal load and constant pressure load.

\section{EVALUATION PROCEDURE}

The methodology adopted within the study for the evaluation of creep cyclic plasticity of the welded joint can be described in two steps.

1. Estimation of residual stress due to welding.

2. Estimation of saturated hysteresis loop using eDSCA within LMM, considering the welding residual stress evaluated in step 1.

\section{Step 1: Estimation of residual stress due to welding}

The residual stress within the weldment is introduced by modeling a heat source and moving it along the circumference of the pipe. A double ellipsoidal heat source model is used in the study, which is similar to the model presented in [8-9]. The model uses two ellipsoidal sources to simulate the experimental effect, with a steep temperature gradient in the front and a slightly less steep temperature gradient at the rear.

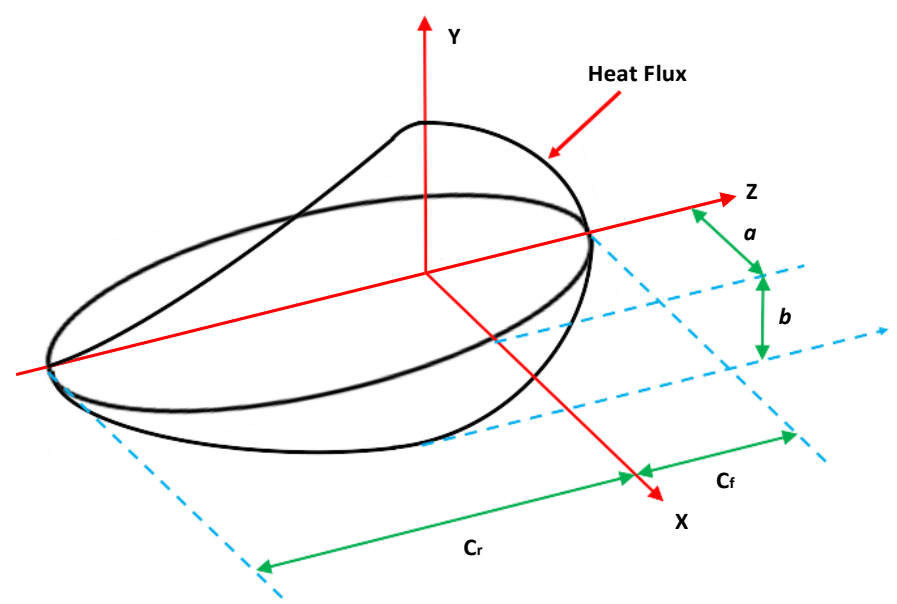

Figure 1 Double ellipsoidal heat source configuration [9]

The power density distribution of the model can be given by

$$
q_{f}(x, y, z, t)=\frac{6 \sqrt{ } 3 f_{f} Q}{a b c \pi \sqrt{f}_{f} \exp }\left\{-3\left(2+\underset{2}{2} \underset{a}{\frac{+}{a}} \quad \frac{y^{2}}{b} \quad \frac{(z+v t)^{2}}{c_{f}^{2}}\right)\right\}
$$

for the front quadrant and

$$
\left.\left.q_{f}(x, y, z, t)=\underset{a b c \pi \sqrt{\pi} \exp \{-3(}{\operatorname{ex} 3 f_{r} Q} \quad \frac{x^{2}}{a^{2}}+\frac{y^{2}}{b^{2}} \frac{(z+v t)^{2}}{c_{r}^{2}}\right)\right\}
$$

for the rear quadrant, where $\mathrm{x}, \mathrm{y}$ and $\mathrm{z}$ are the local spatial coordinates, $\mathrm{Q}=\eta \mathrm{VI}$ is the input power of the welding heat 
source. A user subroutine in DFLUX is developed to apply the volumetric heat flux due to welding.

Table 1 Numerical values for heat source parameters and welding parameters [9]

\begin{tabular}{|c|c|c|c|c|c|}
\hline $\begin{array}{c}\mathrm{a}_{\mathrm{f}} \\
(\mathrm{mm})\end{array}$ & $\begin{array}{c}\mathrm{a}_{\mathrm{r}} \\
(\mathrm{mm})\end{array}$ & $\begin{array}{c}\mathrm{b} \\
(\mathrm{mm}) \\
\end{array}$ & $\begin{array}{c}\mathrm{c} \\
(\mathrm{mm})\end{array}$ & $\begin{array}{c}\mathrm{f}_{\mathrm{f}} \\
(\mathrm{mm})\end{array}$ & $\begin{array}{c}\mathrm{f}_{\mathrm{r}} \\
(\mathrm{mm})\end{array}$ \\
\hline 12.9 & 10.3 & 6 & 5 & 1.4 & 0.6 \\
\hline
\end{tabular}

\begin{tabular}{ccc}
\hline $\mathrm{V}$ (volts) & $\frac{\mathrm{I}(\mathrm{amp})}{225}$ & $\frac{\eta(\%)}{85}$ \\
\hline
\end{tabular}

Step 2: Estimation of saturated hysteresis loop using eDSCA within LMM framework

The theoretical background behind LMM is that the cyclic stress and nonlinear strain can be represented by a series of iterative linear elastic solutions where the moduli vary spatially and with time. The LMM ensures that both equilibrium and compatibility are satisfied at all stages. The LMM has been developed for limit analysis, shakedown analysis, ratchet analysis, and recently it has been further developed to include the eDSCA which helps in accessing the steady-state cyclic behavior of the structure with full creepcyclic plasticity interaction. The eDSCA helps in computing the total strain and stress ranges of the steady state cycle, the start of dwell stress, the associated stress drop and creep strain during the creep dwell. The numerical procedure detailing the evaluation of creep strain using eDSCA has been explained previously in [10]. Hence only a concise version of the numerical procedure is presented here.

Consider an elastic-perfectly plastic body of volume, $\mathrm{V}$ and surface area, S. It is subjected to a general cyclic load history, $\mathrm{F}\left(\mathrm{x}_{\mathrm{i}}, \mathrm{t}\right)$, that can be decomposed to a cyclic temperature history $\theta\left(\mathrm{x}_{\mathrm{i}}, \mathrm{t}\right)$ which acts within the volume, a varying mechanical load $\mathrm{P}\left(\mathrm{x}_{\mathrm{i}}, \mathrm{t}\right)$ and a constant mechanical load, $F^{-}$ $\left(\mathrm{x}_{\mathrm{i}}\right)$. The loads act over a time cycle of $0 \leq \mathrm{t} \leq \Delta \mathrm{t}$.

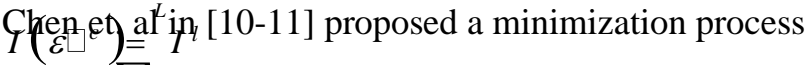
ij $\sum_{i=1}$ to calculate the steady-state cyclic response of a body subjected to an arbitrary cyclic load history, where L is the total number of loading instances and $\varepsilon \square^{c}$ is the kinematic

admissible strain rate. For the defined minimization function, an incremental form is proposed:

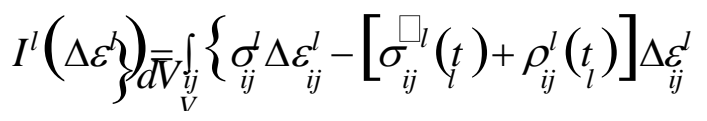

where $\Delta \varepsilon_{i j}^{l}$ is strain increment and $\rho_{i j}^{l}\left(t_{l}\right)$ is the residual stress, which is the sum of previous changing residual stress field increment $\Delta \rho_{i j}\left(t_{l}\right)$ and constant part of the changing residual stress $\rho_{i j}$. In an iterative manner, $\Delta \varepsilon_{i j}^{l}$ is calculated by minimizing the function in Eqn. (1). Assuming $l$ is the number of load instances considered, and $k$ is the number of subcycles required to reach convergence. The residual stress and inelastic strain are calculated based on the elastic stress and the previous accumulated residual stresses at eachincrement. For the load instance $t_{l}$ during the loading cycle, $\Delta \varepsilon_{i j, k+1}\left(t_{l}\right)$ is calculated by:

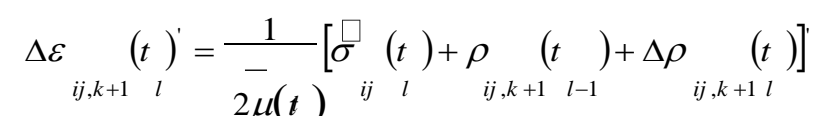

where $\mu_{t}$ is the iterative shear modulus, $\sigma^{\square}$ ij is the associated elastic solution, $\rho_{i j, k+1}\left(t_{l-1}\right)$ is the prior changing residual stress history and $\Delta \rho_{i j, k+1}\left(t_{l}\right)$ is the current changing residual stress associated with that inelastic strain increment. When creep is considered for the load cases, a time hardening creep constitutive relation as given in Eqn. (5) is used. The equivalent creep strain increment is calculated as follows:

$$
\begin{aligned}
& \dot{\varepsilon}^{c}=B \bar{\sigma}^{n} t^{m} \\
& \Delta \bar{\varepsilon}^{c}=\frac{B(n-1) \Delta t^{m+1}(\sigma-\sigma)}{\left(\frac{1}{\bar{\sigma}_{c}^{n-1}}-\frac{1}{\bar{\sigma}_{s}^{n-1}}\right)(m+1)} \\
& \bar{o}_{c}=\left(\frac{\bar{\varepsilon} \square^{F}}{B \Delta t^{m}}\right)^{-1} \\
& \dot{\varepsilon}^{F}=\frac{\Delta \varepsilon^{c}}{\Delta t} \frac{(m+1)}{(n-1)} \frac{\bar{\sigma}_{c}^{n}}{\left(\bar{\sigma}_{s}-\sigma_{c}\right)}\left(\frac{1}{\left(\bar{\sigma}_{c}^{n-1}\right.}-\frac{1}{\bar{\sigma}_{s}^{n-1}}\right)
\end{aligned}
$$

where $\mathrm{B}, \mathrm{m}$ and $\mathrm{n}$ are the creep constants of the material, $\overline{\sigma_{c}}$ represents the creep flow stress, and it is defined as the sum of the start of dwell stress, $\sigma_{s}$ and the residual stress

$\Delta \rho_{i j, k+1}\left(t_{l}\right)$ during the dwell period. Eqn. (7) is used to calculate $\overline{\sigma_{c}}$ and Eqn. (8) is in-turn used to calculate $\varepsilon^{\square}{ }^{F}$,which is the creep strain rate. The next step calculates the residual stress and iterative shear modulus at each increment using the linear solutions previously calculated. The below equation is used for it: 


$$
\bar{\mu}_{k+1}\left(x, t_{l}\right)=\bar{\mu}_{k}\left(x, t_{l}\right) \underset{\sigma\left(\sigma_{l}(x, t)+\rho_{i j}^{\prime}(x, t)\right)}{\sigma^{R}\left(x, t_{l}\right){ }_{k}}
$$

where $t_{k}\left(x, t_{l}\right)$ is the iterative shear modulus at the sub-cycle $k$ for $l^{\text {th }}$ load instance. $\sigma^{R}(x, t){ }_{l_{k}}$ is either temperature-

dependent von-Mises yield stress for the material considered at load instance $t$ or the creep flow stress $\bar{\sigma}_{c} . \rho_{i j}^{r}(x, t)$ is the sum of the constant residual stress field and all previous changing residual stresses at load instance $t_{l}$. The procedure briefly detailed herein determines all the parameters required for the estimation of the saturated hysteresis loop.

\section{CASE STUDY: WELDED FLANGE}

\section{FINITE ELEMENT MODEL, WELDING SIMULATION AND MATERIAL PROPERTIES}

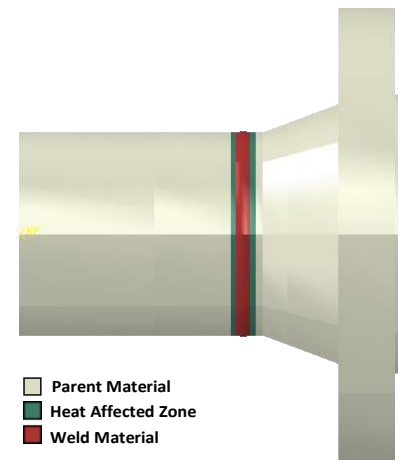

a)

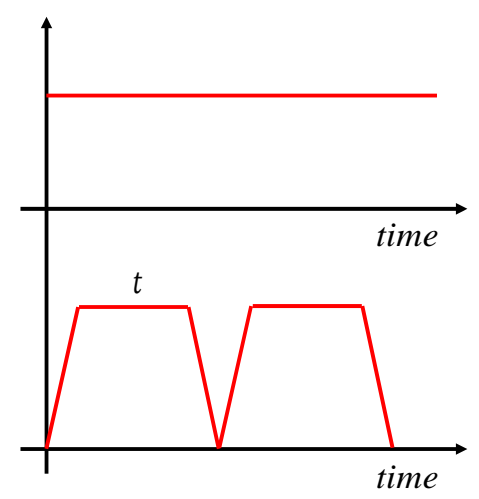

c)

Figure 2 a) Flange-pipe weld with key material zones, b) Mesh used for finite element analysis, c) Loading condition considered for the study

The case study undertaken in this paper considers a P91 flange of rating \#300 that is welded to a pipe. The weldment consists of three material zones; a) Parent Material (PM); b) Heat Affected Zone (HAZ); c) Weld Material (WM) as shown in Figure 2 (a). The study requires the simulation of a moving heat source to generate the residual stress, hence a 3D model is opted over a 2-D or an axisymmetric model for the use in FE simulation. The software used within the study for FE simulation is ABAQUS. The mesh used composes of 6240 elements. The critical area is identified to be within the weldment region, hence the mesh is finely refined within this

region as shown in Figure 2 (b). Using the coupled temperature-displacement element type, the heat flow

simulation is carried out. C3D20R, 20-node quadratic brick elements with reduced integration is used for structural analysis and DC3D20, 20-node quadratic heat transfer brick is used for the heat transfer analysis. As the analysis involves two steps where the results from the initial analysis, estimation of welding residual stress, is used as an input for the next, estimation of saturated hysteresis loop using eDSCA within LMM framework, the boundary conditions and constraints adopted are such that the same is used in both the steps. A symmetric boundary condition about $\mathrm{x}$-direction is applied at the flange head. Towards the pipe end, a plane constraint is implemented so that the pipe may expand radially or axially but the face remains in-plane.

For the heat flow simulation, the welding speed, $v$, is considered to be $6.25 \mathrm{~mm} / \mathrm{s}$. The flange has an outer diameter of $114.3 \mathrm{~mm}$, it takes $58.7 \mathrm{~s}$ for the torch to complete one revolution. Once the moving heat source is simulated, the flange is allowed to cool down to the ambient temperature (which is considered as $30^{\circ} \mathrm{C}$ ), after which it is annealed to a temperature of around $760{ }^{\circ} \mathrm{C}$ for 1 hour and then subsequently cooled down to room temperature.

An elastic-perfectly plastic model is considered to access the creep-cyclic plasticity behavior of the structure. The pipe is subjected to a constant internal pressure and a cyclic thermal load of varying dwell periods (Figure 2 (c)). It is to be noted that only limited material properties were available within the literature for the various zones within the weldment region, hence certain interpolation, extrapolation and assumptions are made to obtain the full range of material properties. Material properties and creep constants used are given in Table 2-7. The conductivity and specific heat are assumed to be the same for all the three regions. Temperature-dependent yield stress is used for the analysis. Temperature-dependent yield stress for the PM was obtained from [12]. The yield stress for WM at $20{ }^{\circ} \mathrm{C}$ is $550 \mathrm{MPa}$, it is then assumed that its variation with temperature is similar to that of the PM and further values were extrapolated. The yield stress of HAZ is considered to be their average. The coefficient of thermal expansion for the different zones are as indicated in Table 2. A slight mismatch is introduced in the coefficient of thermal expansion for WM and HAZ to introduce a stress concentration at the weldment region. For PM, the time-dependent creep constants $\mathrm{B}$ and $\mathrm{n}$ for low temperature and high stress are obtained from [12]. 
They are further extrapolated to obtain values at $600{ }^{\circ} \mathrm{C}$. Eggeler et al. have reported values for B and $\mathrm{n}$ for PM and WM in [13]. A similar ratio is considered in the present study for creep constants, B and $n$ for WM. The values for B and $n$ for HAZ is taken as the average of PM and WM. Creep constant $\mathrm{m}$ is considered to be constant at -0.5 .

\section{RESULTS AND DISCUSSION}

The flange joint is subjected to a constant internal pressure of $2 \mathrm{MPa}$ and a cyclic thermal load of $400{ }^{\circ} \mathrm{C}$. A steady-state thermal analysis is performed to understand the temperature variation across the cross-section of the flange weld (Figure $3)$. The temperature variation is found to be constant throughout the cross-section of the pipe, whereas in the flange head region a thermal gradient is observed. The obtained thermal field is used for the thermal stress analysis within the LMM framework.

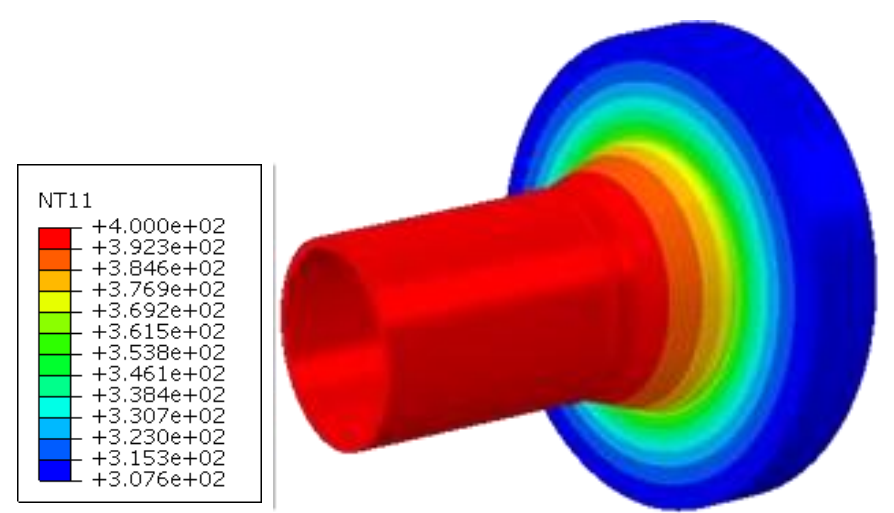

Figure 3 Steady state thermal field of the welded flange

Using the LMM shakedown analysis method, a shakedown limit interaction curve is calculated for the welded flange joint as shown in Figure 4, where the reference constant internal pressure $\mathrm{P}_{0}$ is $2 \mathrm{MPa}$ and the reference cyclic thermal load

is $400{ }^{\circ} \mathrm{C}$. This is done as an aiding step to select various cyclic load points for further analysis and understanding the effect of welding residual stress on creep and cyclic plasticity. It is to be noted that the reverse plasticity region has a wide range in terms of the mechanical load while the range for the thermal load is minimum as above this the structure experiences thermal ratcheting.

The linear elastic analysis is performed for both the pipe pressure and the thermal load as shown in Figure 5. They are further used as inputs towards creep-cyclic plasticity analysis within the LMM framework. From Figure 5 (a) and (b), it can be inferred that the stress produced due to the thermal load is more prominent and the stress concentration is higher towards the weldment region. The welding residual stress concentration is also higher towards the weldment region.
Hence in line with the literature, it is expected that the most critical locations will appear within the weldment region.

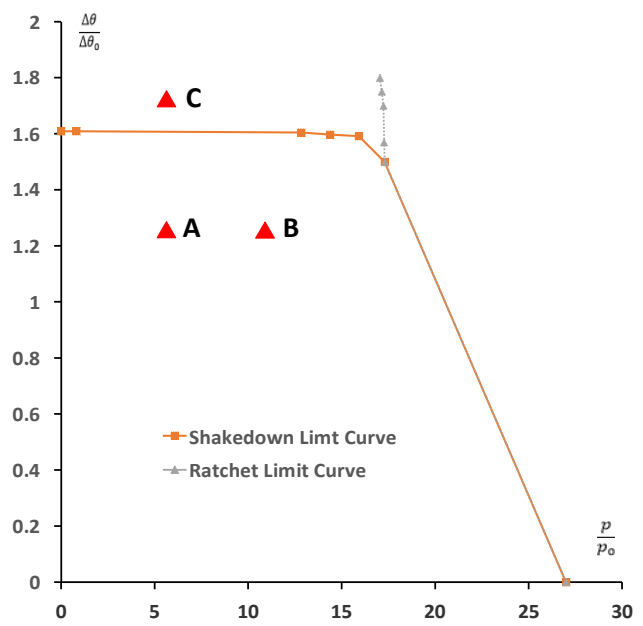

Figure 4 Shakedown-ratchet interaction curve and load points adopted for creep-cyclic plasticity analysis

Table 2 Temperature dependent coefficient of thermal expansion

\begin{tabular}{cccc}
\hline \multicolumn{4}{c}{ expansion } \\
\hline${ }^{\circ} \mathrm{C}$ & 20 & 100 & 750 \\
\hline$\alpha^{M A Z}\left(\mathrm{x} 10^{-5 \circ} \mathrm{C}^{-1}\right)$ & 2.1 & 2.2 & 2.76 \\
\hline$\alpha^{W M}\left(\mathrm{x} 10^{-5 \circ} \mathrm{C}^{-1}\right)$ & 1.65 & 1.728 & 2.16 \\
\hline
\end{tabular}

Table 3 Temperature dependent yield stress

\begin{tabular}{cccc}
\hline \hline${ }^{\circ} \mathrm{C}$ & ${ }_{y}^{M}(\mathrm{MPa})$ & $\frac{{ }_{y}^{H A Z}(\mathrm{MPa})}{y}$ & $\begin{array}{c}W M \\
y\end{array}$ \\
\hline 0 & 503 & 527 & 550 \\
\hline 100 & 478 & 500 & 523 \\
\hline 200 & 453 & 474 & 495 \\
\hline 300 & 444 & 465 & 485 \\
\hline 400 & 424 & 444 & 464 \\
450 & 410 & 429 & 448 \\
\hline 500 & 379 & 397 & 414 \\
\hline 550 & 337 & 353 & 368 \\
\hline 600 & 273 & 286 & 299 \\
\hline 650 & 190 & 199 & 208 \\
\hline 700 & 120 & 126 & 131 \\
\hline
\end{tabular}

Table 4 Specific Heat adopted in the analysis

\begin{tabular}{ccccc}
${ }^{\circ} \mathrm{C}$ & 0 & 500 & 950 & 1000 \\
\hline $\mathrm{J} / \mathrm{kg}{ }^{\circ} \mathrm{C}$ & 440 & 675 & 1000 & 800 \\
\hline
\end{tabular}



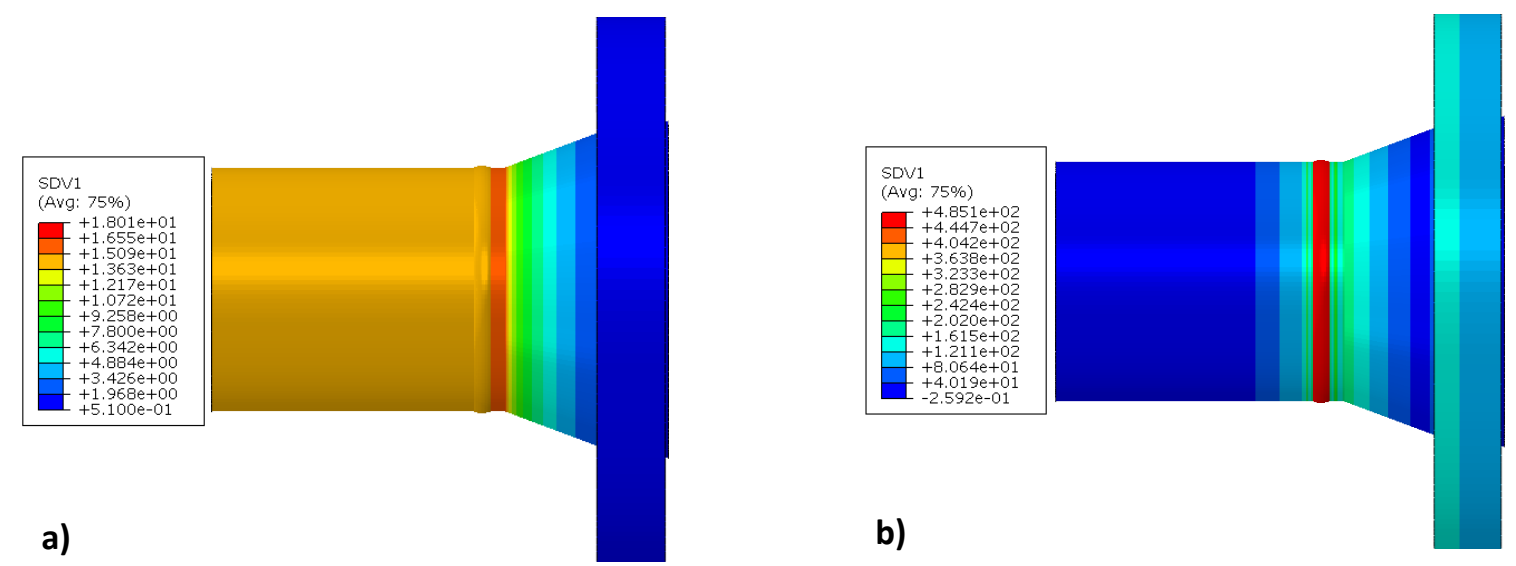

Figure 5 a) Elastic stress contour-mechanical load only, b) Elastic stress contour-thermal load only

Table 5 Temperature dependent conductivity

\begin{tabular}{cc}
${ }^{\circ} \mathrm{C}$ & $k\left(W m^{-1{ }^{\circ}} \mathrm{C}^{-1}\right)$ \\
\hline 0 & 26 \\
\hline 100 & 27 \\
\hline 200 & 28 \\
\hline 300 & 28 \\
\hline 400 & 29 \\
\hline 500 & 30 \\
\hline 600 & 30 \\
\hline 700 & 30.5 \\
\hline 800 & 31 \\
\hline
\end{tabular}

Table 6 Temperature dependent creep constant-B (Eqn.5)

\begin{tabular}{cccc}
${ }^{\circ} \mathrm{C}$ & 500 & 575 & 600 \\
\hline$B^{M}(\mathrm{MPa} / \mathrm{h})$ & $1.78 \times 10^{-40}$ & $1.68655 \times 10^{-31}$ & $2 \times 10^{-31}$ \\
\hline$B^{H A Z}(\mathrm{MPa} / \mathrm{h})$ & $1.60 \times 10^{-40}$ & $1.52 \times 10^{-31}$ & $1.8 \times 10^{-31}$ \\
\hline$B^{W M}(\mathrm{MPa} / \mathrm{h})$ & $1.42 \times 10^{-40}$ & $1.34 \times 10^{-31}$ & $1.59 \times 10^{-31}$ \\
\hline \hline
\end{tabular}

Table 7 Temperature dependent creep constant-n (Eqn. 5)

\begin{tabular}{cccc}
\hline${ }^{\circ} \mathrm{C}$ & 500 & 575 & 600 \\
\hline$n^{M}$ & 14.809 & 12.457 & 11.1 \\
\hline$n^{H A Z}$ & 14.40216 & 12.11477 & 10.6978 \\
\hline$n_{M}^{W}$ & 13.99532 & 11.77255 & 10.3956 \\
\hline
\end{tabular}

Cyclic load point $\mathrm{A}\left(\mathrm{p} / \mathrm{p}_{\mathrm{o}}=5\right.$ and $\left.\Delta \theta / \Delta \theta_{\mathrm{o}}=1.25\right)$, as indicated in Figure 4, is chosen for further analysis. It is well within the shakedown region and is expected to exhibit elastic behavior under normal operating condition. Figure 6 shows the stress contours at steady state with and without welding residual stress for a dwell time of 1000 hours. Without considering welding residual stress, the stress concentration is towards the
WM and nearby regions at the external side of the pipe. The stress relaxation during the end of dwell is minimal. The presence of welding residual stress shifts the stress concentration towards the HAZ-PM region at the inner side of the pipe. It can be seen that there is substantial stress relaxation within the WM region, whereas, near the HAZ-PM region where creep strain is maximum, the stress relaxation is minimum. Figure 7 shows the maximum creep strain region with and without welding residual stress for dwell times of 10,100 and 1000 hours. For all the cases analyzed, the creep strain is maximum within the WM region in the absence of welding residual stress. When welding residual stress is considered, the maximum creep strain shifts to the HAZ-PM region towards the inner side of the pipe. Figure 8 presents the plastic strain contours with and without welding residual stress for a dwell time of 1000 hours. In the absence of welding residual stress, the plastic strain is maximum within the WM region. It is to be noted that the plastic strain during unloading is substantially higher than during loading. When welding residual stress is also considered, the critical area shifts to the HAZ-PM region towards the inner side of the pipe. During loading and unloading, the region with maximum plastic strain concentration remains the same but during loading it is highly concentrated within this region. It can be inferred that the stress redistribution while considering the welding residual stress shifts the critical location from the WM to HAZ-PM region.

Figure 9 presents the hysteresis loop at the most critical point for dwell times of 10, 100 and 1000 hours. The critical location without welding residual stress is considered to be within the WM region and the critical location with welding residual stress is considered to be near the HAZ-PM region. The presence of welding residual stress, produces an open hysteresis loop for all three dwell times considered. Plasticity is observed during loading and unloading. Plastic strain 

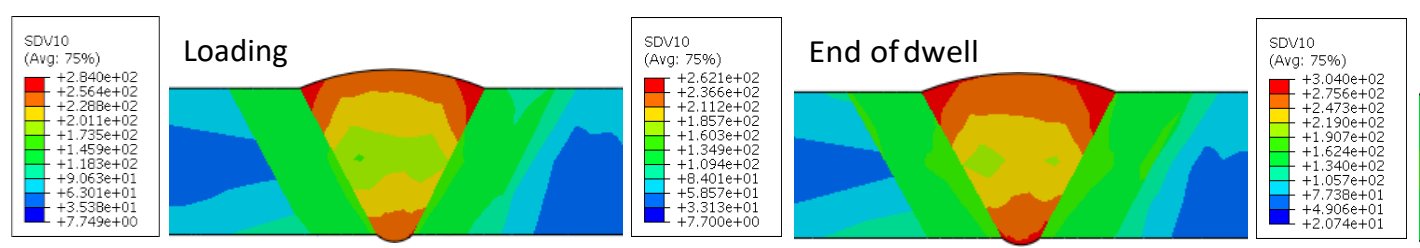

Unloading

a)
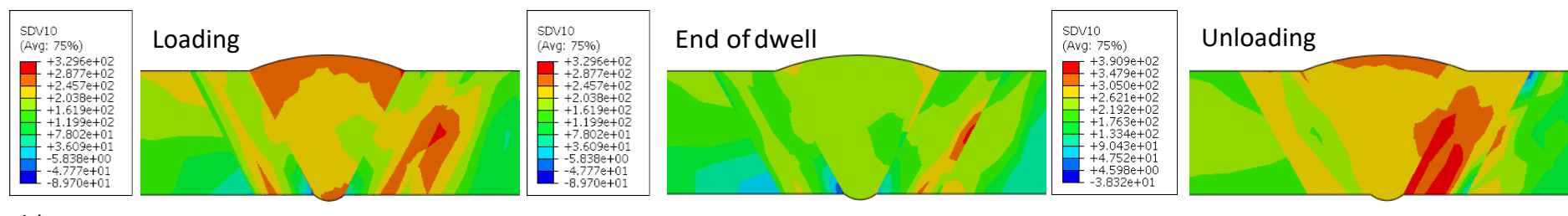

b)

Figure 6 Steady State Stress for 1000 hours dwell time a) Without welding residual stress; b) With welding residual stress

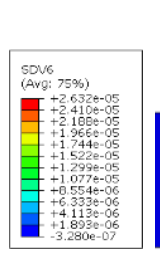

a)

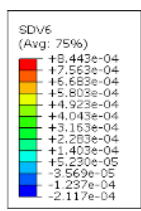

b)
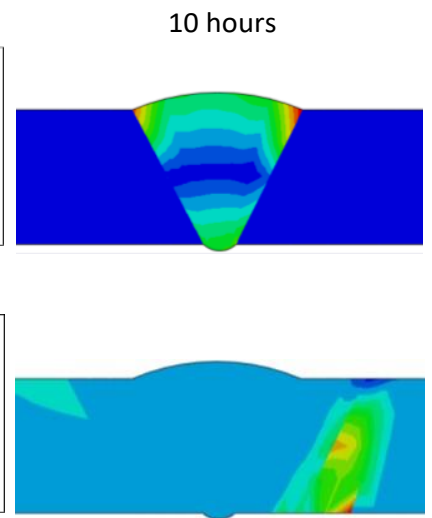

(a)

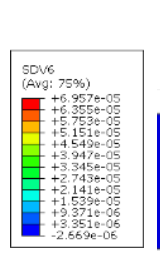

a)

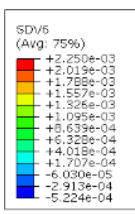

b)

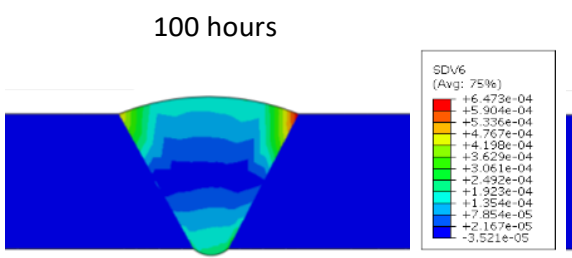

a)

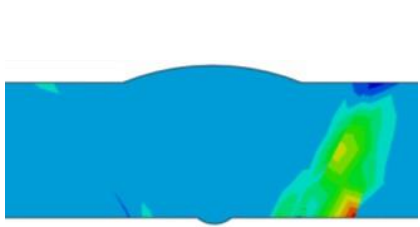

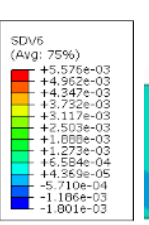

b)

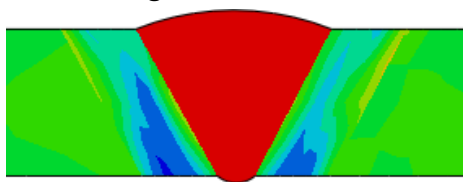

Figure 7 Creep Strain a) Without welding residual stress; b) With welding residual stress
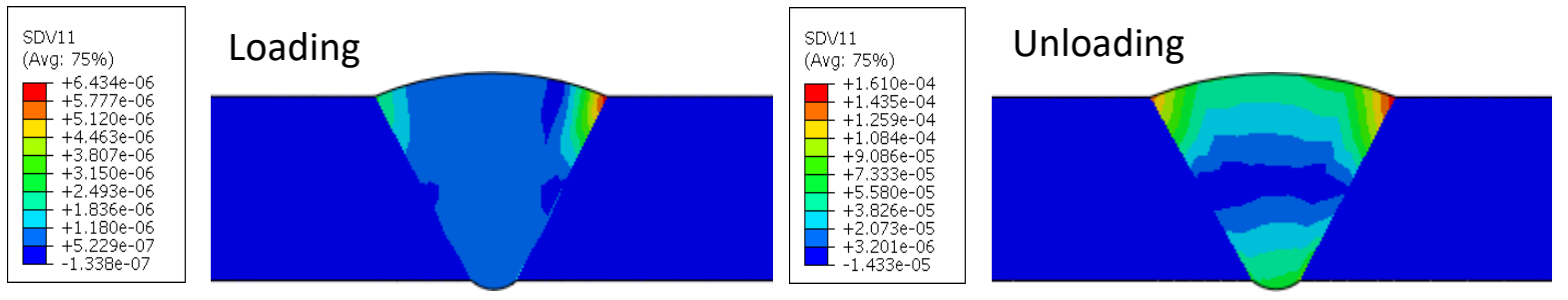

a)
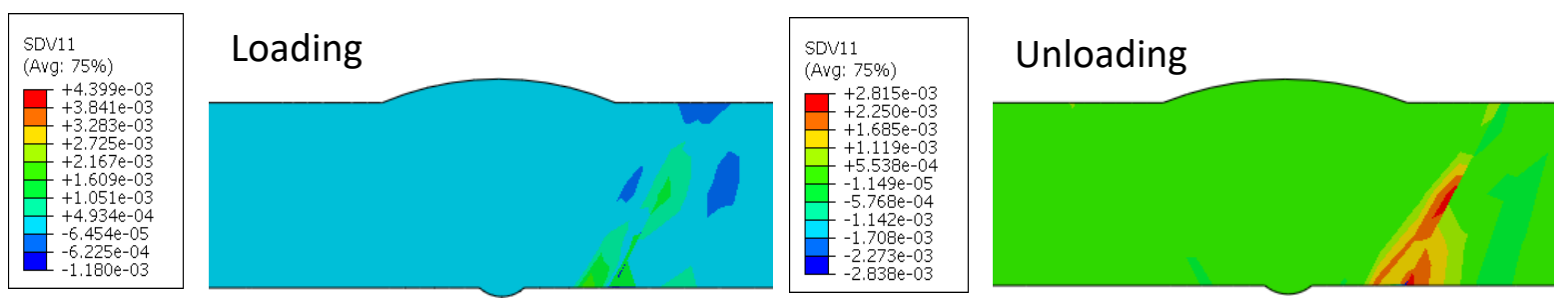

b)

Figure 8 Plastic Strain for 1000 hours dwell time a) Without welding residual stress; b) With welding residual stress

produced during unloading is not large to reverse the strain produced during creep dwell and loading hence an open loop is observed. This indicates cyclically enhanced creep ratcheting. The plastic strain increment during loading and 
unloading are within similar ranges for all the dwell times but the creep strain is found to be increasing substantially with the dwell time. The hysteresis loop without considering the effect of welding residual stress is also presented in Figure 9 for a dwell time of 1000 hours (indicated as $1000 \mathrm{hrs}-N o$ res). A closed loop is observed where the creep strain is compensated by the plastic strain during unloading. The contours presented in Figure 8 also show a larger plastic strain during unloading. From Figure 9 the increase in creep strain with welding residual stress is much larger than without welding residual stress. It is to be noted that the start and end of creep stress for the 1000 hours dwell time are in similar range but the critical location shifts from the WM region to the HAZ-PM region and brings about a substantial change in the creep strain. This is due to the variation of the temperature and the creep constants $\mathrm{B}$ and $\mathrm{n}$ at both the locations.

In order to understand the influence of higher mechanical load on the cyclic plastic and creep behavior of the welded flange, another cyclic load point- $\mathrm{B}\left(\mathrm{p} / \mathrm{p}_{\mathrm{o}}=10\right.$ and $\left.\Delta \theta / \Delta \theta_{0}=1.25\right)$ as indicated in Figure 4 is analyzed. Figure 10 presents the comparison of the hysteresis loop between cyclic load points A and B for a dwell time of 100 hours with welding residual stress. It is seen that the increase of mechanical load has no effect on the response of the structure. This is because though the mechanical load is increased the stress due to thermal load and welding residual stress is very large that it has minimal effect.

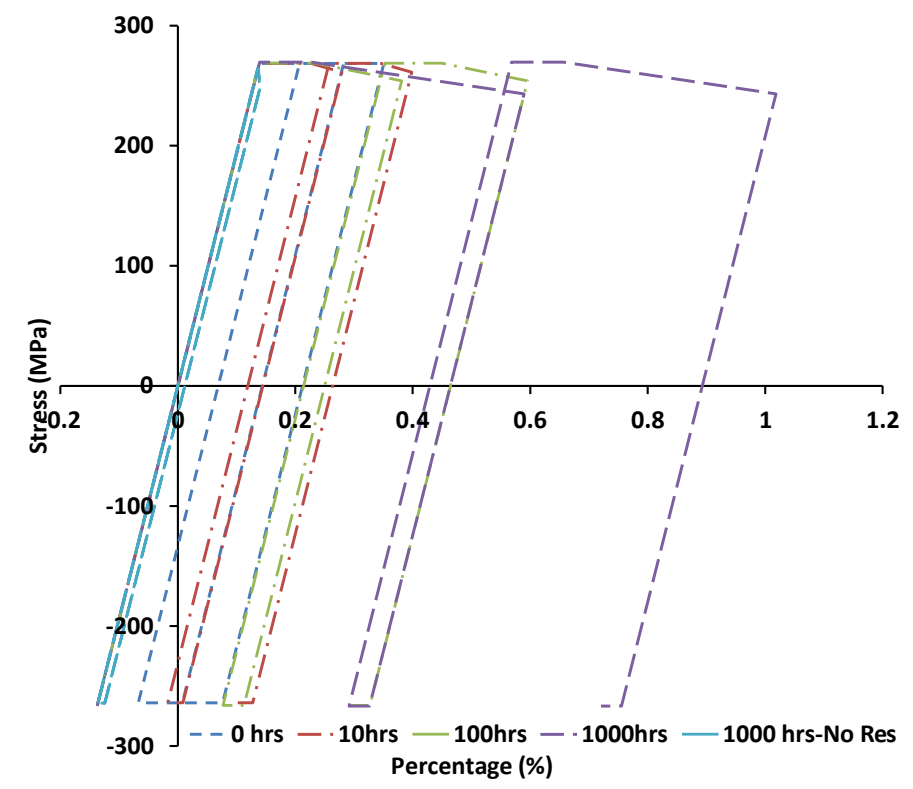

Figure 9 Hysteresis loop for cyclic point-A

Cyclic load point $-\mathrm{C}\left(\mathrm{p} / \mathrm{p}_{\mathrm{o}}=5\right.$ and $\left.\Delta \theta / \Delta \theta_{\mathrm{o}}=1.7\right)$, where the thermal load is further increased is analyzed to understand the effect of increasing thermal load on the structural response of the welded flange. Figure 11 presents the comparison of the hysteresis loop between cyclic load points $\mathrm{A}$ and $\mathrm{C}$ for a dwell time of 100 hours with welding residual stress. An increase in the thermal load increases both the accumulation of plastic strain during loading and creep strain. It has a detrimental effect on the structural integrity of the flanged joint. For all the analysis carried out, it is seen that the presence of welding residual stress leads to an open hysteresis loop indicating creep ratcheting.

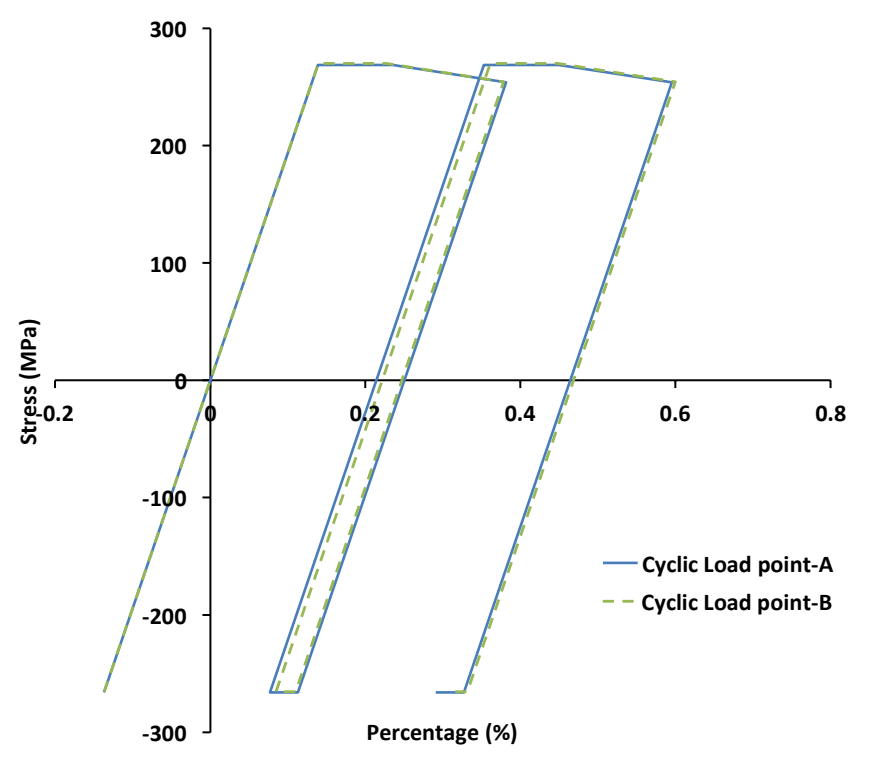

Figure 10 Hysteresis loop comparing cyclic point-A and cyclic load point-B for 100 hours

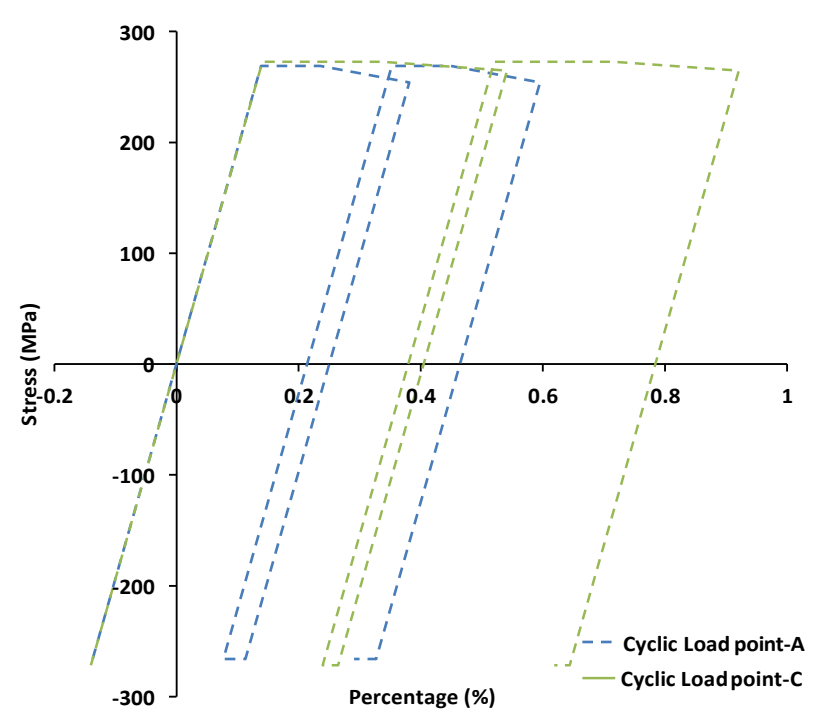

Figure 11 Hysteresis loop comparing cyclic point-A and cyclic load point-C for 100 hours 


\section{CONCLUSIONS}

Creep-cyclic plasticity behavior of the welded flange with welding residual stress subjected to a constant mechanical load and a cyclic thermal load is analyzed using the eDSCA within LMM framework. The welding residual stress is generated using a moving heat source with the help of an inhouse developed D-FLUX subroutine. Temperaturedependent material properties and creep constants are used. The main results obtained from this work are summarized as below:

- The presence of welding residual stress is found to have a substantial effect on both the plastic strain and creep strain, with both of them increasing.

- At higher thermal load condition, the presence of welding residual stress leads to higher plastic strain accumulation during loading.

- For the considered range, an increase in the mechanical load has minimal effect on the creep-cyclic plasticity of the pipe.

- The presence of welding residual stress leads to an open hysteresis loop indicating creep ratcheting. The absence of welding residual stress led to a closed hysteresis loop.

- For the cases analyzed, the most critical zone with welding residual stress was found to be at the HAZ-PM region whereas without the effect of welding residual stress it was found to be near the WM.

\section{ACKNOWLEDGMENTS}

The authors gratefully acknowledge the support of the University of Strathclyde, the East China University of Science and Technology, and the 111 Project (B13020) during the course of this work.

\section{REFERENCE}

[1] P. J. Withers and H. K. D. H. Bhadeshia, "Residual stress. Part 2 - Nature and origins," Mater. Sci. Technol., vol. 17, no. 4, pp. 366-375, 2001.

[2] P. J. Withers, "Residual stress and its role in failure," Reports Prog. Phys., vol. 70, no. 12, pp. 2211-2264, 2007.

[3] H. Chen and A. R. S. Ponter, "Linear matching method on the evaluation of plastic and creep behaviours for bodies subjected to cyclic thermal and mechanical loading," Int. J. Numer. Methods Eng., vol. 68, no. 1, pp. 13-32, 2006.

[4] Y. Gorash and H. Chen, "A parametric study on creep-fatigue strength of welded joints using the linear matching method," Int. J. Fatigue, vol. 55, pp. 112-125, 2013.

[5] Y. Gorash and H. Chen, "On creep-fatigue endurance of TIG-dressed weldments using the linear matching method," Eng. Fail. Anal., vol. 34, pp. 308-323, 2013.

[6] Y. Gorash and H. Chen, "International Journal of Pressure Vessels and Piping Creep-fatigue life assessment of cruciform weldments using the linear matching method," Int. J. Press. Vessel. Pip., vol. 104, pp. 1-13, 2013.

[7] D. Barbera, H. F. Chen, and Y. H. Liu, "On the Creep Fatigue Behavior of Metal Matrix Composites," Procedia Eng., vol. 130, pp. 11211136, 2015.

[8] J. Goldak, A. Chakravarti, and M. Bibby, "A new finite element model for welding heat sources," Metall. Trans. B, vol. 15, no. 2, pp. 299-305, 1984.

[9] M. Abid and M. J. Qarni, "3D Thermal finite element analysis of single pass girth welded low carbon steel pipe-flange joints," Turkish J. Eng. Environ. Sci., vol. 33, no. 4, pp. 281-293, 2009.

[10] H. Chen, W. Chen, and J. Ure, "A Direct Method on the Evaluation of Cyclic Steady State of Structures With Creep Effect," J. Press. Vessel Technol., vol. 136, no. 6, p. 061404, 2014.

[11] C. Fatigue, D. Assessment, O. F. V. Weld, P. With, E. Direct, and S. Cycle, "PVP2018-84568," 2018.

[12] NIMS and Japan, Creep and rupture data of heat resistant steels, https://smds.nims.go.jp/MSDS/en/sheet/Creep.htm , [accessed 2018-11-30] .

[13] G. Eggeler et al., "Analysis of creep in a welded \{P91\} pressure-vessel," Int. J. Press. Vessel. Pip., vol. 60, no. 3, pp. 237-257, 1994. 